\title{
BitÁcora Zombi, PRÁcticas del DibUjo de PAISAJE EN SAN JosÉ. VISUALIDAD, IMAGEN Y DESPLAZAMIENTO POR LA RUINA MODERNA EN INSTAGRAM
}

\author{
Bitácora Zombi, Landscape Drawing Practices in San José. Visuality, \\ Image, AND DisPlacement THROUGH MOdERn Ruin IN INSTAGRAM
}

\author{
Rodolfo Rojas-Rocha* \\ DOI: https://doi.org/10.29043/liminar.vl8i2.779
}

\begin{abstract}
Resumen: En este artículo se abordan aspectos teórico-prácticos de la Bitácora Zombi como acto narrativo y representativo del paisaje arquitectónico y urbano de San José, Costa Rica. Se sustenta en una mirada estética del entorno, con el fin de potenciar la información del espacio público al evidenciar conflictos de convivencia y marginación en el régimen escópico. A su vez, se reflexiona sobre la reconfiguración de la construcción visual de la realidad a partir de nociones como: ciudad posmoderna, hauntologías, ecología zombi, ruina moderna, turismo negro y ecología del miedo. Se emplean dos herramientas metodológicas de observación aportadas por la sociología visual: la primera se sustenta en la mirada urbana propuesta por el flâneur creativo mediante el andar figital (físico y digital) ejercido por derivas geolocalizadas, y la segunda implica la elaboración de un dibujo creativo del entorno transformado en cuaderno y documentación de viaje, que se subió a la red social Instagram, como arte urbano en línea.
\end{abstract}

Palabras clave: arte urbano, arte digital, conflicto social, flaneurismo, redes sociales, Instagram.

Abstract: This article deals with theoretical and practical aspects of the Bitácora Zombie as a production and representation of the architectural and urban landscape of San José (Costa Rica). It is based on an aesthetic view of the environment, potentiating information about the public space by evidencing conflicts of coexistence and marginalization through the scopic regime. At the same time, the article discusses some theoretical notions that reconfigure the visual construction of reality: postmodern city, hauntology, zombie ecology, modern ruin, black tourism, and fear ecology. Two methodological observation tools provided by visual sociology are used. The first addresses an urban view proposed by the creative flâneur through the "phygital" (physical and digital) walk carried out through geo-located wanderings. The second tool involves the development of a creative urban sketch or drawing of the environment transformed into a notebook and travel document uploaded to the Instagram social network.

Keywords: urban image, digital arts, social conflict, flaneurism, social network, Instagram.

\footnotetext{
* Rodolfo Rojas Rocha. Pintor, dibujante, artista visual y mediático, profesor de la cátedra de Diseño Pictórico de la Escuela de Artes Plásticas e investigador en el Instituto de Arte (IIARTE) de la Universidad de Costa Rica. Temas de especialización: imagen plástica, performance, arte visual, arte mediático. Correo electrónico: RODOLFO.ROJASROCHA@ ucr.ac.cr. ORCID: https://orcid.org/0000-0003-1824-8146
}

Enviado a dictamen: 11 de diciembre de 2019. Aprobación: 30 de abril de 2020.

Revisiones: 2. 


\section{Introducción}

E n este artículo me propongo oponer la realidad observada en el espacio público frente a la fábula urbana, narrada a partir de una práctica artística en desplazamiento, simbolizando el atributo ficcional de San José, Costa Rica, en tanto “ecología zombi”. Esta se trata de una ecología artificiosa compuesta de "ruinas modernas" que representan conflictos citadinos de distinta naturaleza y realidad social en decrecimiento. También, se incorporan esas dificultades en el universo físico y digital, es decir, en la dimensión figital.

Se parte de la Bitácora Zombi, empleada en lugares figurados por el dibujo de paisaje con claves abstractas en contextos compuestos de "ruinas modernas", donde la metodología zombi interviene proponiendo un modelo tomado mayormente de la sociología visual (De Miguel, 2003) y de los estudios visuales; además, se asocia a rutas de exploración socioespacial.

Este método artístico interdisciplinario articula tres fases operativas: la deriva urbana, el dibujo cromático in situ y la plataforma de Instagram, que conforman la investigación-creación empleada en la paisalogía de San José.

La metodología zombi, compuesta de una lista de imágenes de control por la observación directa, sirve de testimonio de la crisis del gran relato moderno al configurar territorios habitados por minorías y colectivos. Desde el prisma metodológico zombi se introduce un quehacer plástico, visual y digital, unido a una visión nihilista, distópica y desesperanzadora de la ciudad muerta. En el contexto de la ciencia ficción estos recorridos, en una ciudad de fantasía atravesada por rutas virtuales, se vinculan a la phygitalización. Mediante esta técnica, la imagen fija del dibujo se muda a la fotografía digital al narrar personajes, tiempos y espacios visuales del paisaje local, y al categorizar niveles de ver la realidad social, cultural, económica y política. Con la ayuda de estos recursos se propone un modelo interdisciplinario que aplica procedimientos y marcos teóricos propios.

Esta metodología demarca cinco rutas de deambulación real/virtual en San José Centro que aportan lindes, procesos, pericias y modos de caminar, aplicando el flaneurismo figital, el cual es registrado en Instagram como arte urbano en línea.

Para lograr esos cometidos se inició la primera deriva en el patrimonio republicano de ruinas espectrales por el Parque Central, la Asamblea Legislativa y la Plaza de la Democracia. La segunda deriva, del modernismo formalista, arrancó a partir del arte público, emplazado en la zona peatonal de la Avenida Central. La tercera ruta corresponde al cuerpo bio-geopolítico del migrante, en el Parque de la Merced y sus contornos. La cuarta ruta, de cuerpos-sin hogar o itinerantes, se sitúa en la zona Rincón Cubillos, Pitahaya, Coca Cola y Paso de la Vaca. Por último, la quinta ruta recorre Barrio Escalante.

También, partimos de la operatividad de la metodología zombi. ¿Cómo se interrelaciona la ficción, en la representación visual con la experiencia urbana? ¿Cuál es la función de la Bitácora Zombi subida en Instagram, vista como territorio zombi de ruinas modernas? ${ }^{1}$

En tal sentido, para responder a estas cuestiones se empieza mencionando, a nivel teórico, la estructura conceptual del artículo. Este se organiza en tres partes que toman en cuenta la imagen, el desplazamiento y la ficción. La imagen aporta el sentido perceptual hacia una lectura de la comunidad, vista en la representación gestáltica y semiótica inmersa en un hipotético paisaje zombi, donde la vejación del ser humano es el eje principal ante la espiral urbana. Específicamente, la imagen visual, por otro lado, es un dispositivo inmaterial y material de claves emocionales, mentales, corporales, visuales, olfativas y hápticas a nivel perceptivo. El desplazamiento activa lo sensorial, las creencias y las motivaciones. Así, la ficción recrea la marcha al regenerar una utopía mental en el transcurso del movimiento del cuerpo, que sueña y pondera el conflicto urbano al conectarse con el mundo virtual.

Específicamente, el artículo se divide en las siguientes partes: ecología del miedo; la ruina y la hauntología; flaneurismo phygital; turismo negro por Instagram; metodología zombi; derivas urbanas en la cartografía de San José, y un apartado final de conclusiones. 
A partir de esta estructura en siete partes, se desarrollan cuatro ejes teóricos compuestos de nociones y conceptos con enfoques interdisciplinarios.

El primer eje se concentra en la imagen: la percepción, la visualidad, el régimen escópico (Jay, 2003) y la iconografía (Brea, 2006; Buci-Glucksmann, 1986; Fontcuberta, 2016; Mitchell, 2014; Tomás, 1998).

El segundo eje abarca la ficción en lo distópico en el contexto de la ciudad posmoderna (Amendola, 2000; Davis, 2007; Fukuyama, 1989; García Canclini, 1995; Rosler, 2017), donde hay un estado fenoménico más allá de lo moderno. Se citan los zombies studies (Fernández, 2011; Platzeck, 2016) asociados a la "ruina moderna" (Scott, 2015; Vidal, 2013) y el monstruo en la ecología del miedo (Davis, 2001; Mestre y Zappi, 2020), marcados por la hauntología. Asimismo, se recalcan nociones como el panopte y la biopolítica (Foucault, 2007; Lacan, 1966) en relación transversal con el primer eje de la imagen y la visualidad.

El tercer eje abarca el desplazamiento en la perspectiva urbana (Déotte, 2015) mediante flaneurismo (Baudelaire, 2017; Benjamin, 2005; Careri, 2002; Solnit, 2015), usando la deriva urbana realizada desde el turismo negro (Augé, 1998; Debord, 1958; Rey y Rodríguez, 2009).

Por último, el cuarto eje entrecruza la tecnología con la ficción geopoética (Lévy y Bouvet, 2018), entre la virtualidad de la geolocalización figital (Lévy, 2003; Rojas, 2017), por mediación de la pantalla (Márquez, 2015; Soulages, 2012), plataformas (Srnicek, 2018) y redes sociales.

\section{Ecología del miedo}

\section{Percepción y régimen escópico: ojo y mirada}

La ciudad, en su aspecto más abstracto, existe en la generalidad del régimen escópico, asistido por la historia de la cultura moderna, regulando y reorganizando operaciones de la visualidad en el contexto del logocentrismo.

Jay afirma que el sentido de la vista incide sobre las maneras de leer la modernidad visual:
Con frecuencia se ha sostenido que la era moderna estuvo dominada por el sentido de la vista de una manera que la distingue de sus predecesoras premodernas y posiblemente de su sucesora posmoderna. Comenzando por el Renacimiento y la revolución científica, en general se estima que la modernidad ha estado resueltamente marcada por el oculocentrismo. El invento de la imprenta, de acuerdo con el familiar argumento de MacLuhan y Ong, fortaleció la supremacía de lo visual instigada por invenciones tales como el telescopio y el microscopio (Jay, 2003:221).

Entonces, ¿cómo opera la supremacía de lo visual aplicada al dibujo de paisaje? La supremacía de lo visual desde el paisaje articula la imagen escópica en la producción de contenidos a partir de la mirada del artista, la cual es definida por las circunstancias socioespaciales, que respaldan los aspectos fisiológicos, cognitivos, tecnológicos, formales y materiales del contexto.

En el régimen escópico se configuran íconos materiales que forman parte de una ecología del ojo, donde el receptor del paisaje recrea fenómenos, convertidos en significantes de un tejido perceptual repleto de combinaciones oculares. En el régimen escópico, el caminar (Careri, 2002; Solnit, 2015) permite emplear representaciones mentales de la cultura visual del lugar público. Igualmente, en esa activación perceptiva y representativa se da la apropiación de los "actos de ver, como actos cargados de significancia y valor cultural" (Brea, 2006:23), donde el ojo-urbano se descompone en el espacio abierto. Más aún, el régimen visual del receptor activa la comunicación en el ambiente al contribuir en la respuesta del cuerpo en movilidad.

\section{Monstruosidad zombi y espacio urbano}

Al mismo tiempo, asociamos lo monstruoso a la anomalía y a la custodia en el espacio visual. El monstruo rompe el canon perceptual de belleza y recuerda a Argos Panoptes, personaje mitológico y vigilante con cien 
ojos, que instaura el dominio visual (Limare, 2015) en el espacio arcaico. Por ende, una ciudad patrullada en la era posapocalíptica (Mestre y Zappi, 2020) podría recrear el estado de una catástrofe sanitaria o el declive de la humanidad a causa de la fuga de un virus hecho en un laboratorio, dando importancia a la monitorización sistemática del espacio visual. En este escenario de dominio y horror se vislumbra la anomalía de la mirada en la organización del azar, en la cual el caminante construye un sentido teleológico y sobrenatural de los recorridos espaciales.

Según José Platzeck: "En la cultura occidental, el monstruo es presentado como una alteración respecto a la norma de lo humano, es una figura que pone en tensión los regímenes de inteligibilidad epistémica y política de los cuerpos normalizados" (2016:236).

En Los anormales, Foucault (2007) se refiere a la persona marginada en la institución, quien está por fuera de la ley, el poder y el saber, lo que indica, por supuesto, un vínculo moral con lo teratológico que no garantiza el patrón común de lo corpóreo. Como indica Platzeck:

\begin{abstract}
Foucault se ocupa de la figura del monstruo como antecesor del normal. Por un lado, el monstruo es desarrollado en relación con el poder soberano, el monstruo es la excepción "de la naturaleza y de la ley”, cuyo marco de referencia es siempre jurídico. Foucault se detiene en la aparición del "monstruo moral", que, en contraposición al monstruo biológico, es definido como una desviación del comportamiento (Platzeck, 2016:236).
\end{abstract}

Esas metáforas del monstruo antisocial, antipatrón común y dominante las afiliamos a la paradoja de la agresividad urbana y a la mutación genética por error. Entonces, el cuerpo-ojo es el objeto del escrutinio político (Foucault, 2007) y de la vida privada en la movilidad urbana (Carracedo, 2002) como una desviación de valores.

Más aún, la monstruosidad la asociamos al origen cultural del zombi, el cual parte de la mitología de origen africano y del mestizaje étnico iniciado por la civilización occidental:
La monstruosidad zombi nos remite a la cultura haitiana, al rito vudú capaz de volver a la vida —o quizás "reanimar" - a un cadáver, que será controlado por quien realice el rito. Este monstruo puede ser leído de manera ambivalente: como una figura de resistencia en tanto permite invertir la relación esclavo-amo (es decir habilita la posibilidad de poner al amo a trabajar en el lugar del esclavo a través del rito) [...] (Platzeck y Torrano, 2016:236).

Ciertamente, el zombi (Fernández, 2011) remite a la condición de resistencia biopolítica del esclavo, construido por el colonialismo y el imperialismo, e impugna la explotación (Platzeck, 2016).

Hipotéticamente el zombi, cadáver-viviente, compuesto de vísceras putrefactas y órganos expuestos debido al contagio de una pandemia multifactorial, constituye el espejo posthumano (Fernández, 2011:22) como estado de introspección en la "ciudad zombi", la cual es recreada en el horror film de Hollywood gracias a la tecnología de la imagen en movimiento.

Por esta razón, en la "ciudad zombi" el cuerpo se identifica por el dominio del significante en Lacan (1966), limitado por el suspenso, lo íntimo y lo corpóreo en la triada compuesta de lo real, lo simbólico y lo imaginario. Por eso, se delimita el significante material del cuerpo fraccionado y abyecto como un desecho orgánico mental y, a la vez, simbólico.

Lo monstruoso en el cuerpo social, por ende, está supeditado a la esquizia de la mirada, alterada en el acto mismo de la angustia y la castración (Lacan, 1966) partícipe de la pulsión óptica. El régimen de lo real del territorio pondera maneras de ver y ser visto, cuando el cuerpo-ojo lleva la visibilidad de la subjetividad desde lo orgánico a lo urbano.

También, se vincula la otredad del zombi en la condición (Platzeck, 2016) caótica de la urbe, que calza perfectamente en entornos ajenos donde destaca la violencia colectiva - grupos ideológicos, sectas, fundamentalismos nacionalistas y religiosos, pandillas, crimen organizado, violencia verbal en redes socialesasí como la barbarie grupal, determinada por la pulsión óptica y la autoridad en la ecología del miedo. 


\section{Iconofília, iconofobia y ecología del miedo}

Para entender la noción de miedo (Davis, 2001), como angustia y desconfianza en los reinos de la imagen y sus territorios, es necesario delimitar la ecología (ökologie) a partir de las palabras griegas logos, traducida como razón o palabra, y oîkos, casa, sitio donde se habita o se halla algo afín a los seres vivos y al ambiente circundante. Extrapolando este sentido, la ecología de la imagen se extiende a la ecología urbana, respaldada por un sistema iconográfico y social de sitios donde operan mecanismos, estrategias y estructuras del espacio habitado por lo visual.

Una ecología del miedo evidencia el conflicto multicultural e interracial de la ciudad, donde la intersubjetividad del habitante construye la estructura diegética de imaginarios en riesgo, fusionando retóricas, discursos y conciencias.

También, la ecología del miedo (Davis, 2001) remite a la antigua inspección de la imagen. La "iconofobia" (Tomás, 1998:26) y la antipatía hacia la veracidad de la imagen premoderna reafirman la preconcepción dualista espíritu/cuerpo desde la visión platónica, prejuicio apoyado por la teología del texto sagrado. En ese sentido, el conflicto ideológico tiene su raíz en la sustancia del lenguaje oral/escrito, al afirmarse que la "voz de dios prohíbe las imágenes, el dedo de dios escribe" (Tomás, 1998:25). En el Antiguo Testamento el uso litúrgico y la legitimación divina del texto apotropaico desafían el ícono por su condición sensual, totalizante y objetual (Tomás, 1998). El temor irracional a la representación visual tiene su origen en lo material y en el soporte significante, en cuya lectura judeocristiana reina una gran tradición de rechazo a la carne y a lo perceptual, de ahí la relación paradójica con la ruina como espacio de ficción.

\section{La ruina y la hauntología}

\section{¿Qৃué es una ruina?}

La ruina se identifica con el patrimonio espacial e inmaterial, el cual es incapacitado en el tiempo porque la sociedad así lo exige y lo demanda. Es un bien mueble que marca un recorrido repleto de contaminación histórica, donde el andante se incluye en la nada en relación con hechos que ya no son más, y otros que aún no existen porque no han acontecido. Esos fenómenos reflejan la decadencia de un pasado histórico que se mantiene en un estado esencial.

En fin, se proponen cuatro tipos de ruinas que funcionan en tanto metáforas de la ciudad que se recorre en el tiempo: ruina barroca, ruina moderna e industrial (Vidal, 2013), ruina posmoderna (Amendola, 2000) y ruina fantológica.

\section{Ruinabarroca}

La ruina barroca es vacía y variada; se compone de rocailles irregulares y orgánicas, sumadas al exceso retorcido de la superposición de texturas y efectos visuales propios de las vanités y del pathos de la contrarreforma católica. De ahí que el savoir-faire en el trabajo del oro, en el palacio barroco racionalista, muestra una sociedad cortesana inmersa en el discurso teatral. En términos de efectismo de la ciudad del rey se extienden también el jardín pintoresco del rococó y la galería de arte. Encima, el divertimento, el hedonismo, los recorridos y el flirteo determinan ejercicios de ilusión óptica. Luego, el espacio barroco se convierte en ruina premoderna porque es cuestionada por la cultura liberal de la guillotina de la Revolución francesa, marcada por el orden racional que glorifica el valor constitucional, republicano, nacional y populista.

\section{Ruina moderna e industrial}

Posteriormente, la ruina industrial se asocia con el placer de la image flux (Buci-Glucksmann, 2003) de la sociedad de consumo con productos multiplicados al infinito, que genera réditos de una economía óptica en decadencia y resemantiza el movimiento romántico mediante la expresión de emociones del paisaje de la Belle Époque.

En el contexto de la ruina industrial del siglo XIX y los monumentos de las vanguardias del siglo XX, la 
imagen de la ruina moderna se asocia al cuestionamiento del funcionalismo, a la destrucción de la forma clásica y al consumo de la espacialidad pragmática.

En ese sentido, la ruina moderna se erige desde una distopía literaria contraria a la idea de progreso. Por ejemplo, en 1984 Orwell recrea la sociedad industrial, donde la repetición masiva de imágenes conlleva la injusticia, la pobreza y la marginalidad, determinadas por la estructura narrativa temporal o sintáctica de un espacio social, por lo que se implanta una iconosfera de la desesperanza a partir de la reproducción de la imagen.

Lo reafirma Benjamin (2013) en La obra de arte en la época de reproductibilidad técnica, donde reflexiona sobre la ecología visual desde el inicio de la expansión de la imagen artística extraída del museo de arte. Esta iconosfera institucional, lugar de interpretación de la proliferación de imágenes, está emparentada con la acumulación territorial y la "pérdida del aura" (Benjamin, 2013:22) del espacio estético tradicional, que delimita el sitio arquitectónico posmoderno dentro del cual transita el flâneur, el artista, el usuario, el turista y el transeúnte.

\section{Ruina posmoderna}

Francis Fukuyama (1989) anuncia el fin de la historia para validar la desilusión del progreso sobre la invención, donde la segregación, el desgaste de géneros arquitectónicos y la segmentación de la geografía urbana se desligan de la idea de innovación. En la ruina posmoderna, la planificación territorial conlleva la arquitecturización del pasado manufacturero, el cual se enlaza a la iconosfera del consumo cultural de la era digital, donde el espacio es incalculable.

Específicamente, se hace alusión directa a la triada: Internet-virtualidad-geolocalización. Ella está determinada por una historia alterna, desde la lectura epistemológica, porque incita al cuestionamiento de la razón objetiva por medio de la mirada neoecléctica en la ausencia de la historia, apostando por una futurología de anticipación de una realidad ficticia.

Veamosel caso de Dubai, lugar mediáticoeinteligente difusor de la imagen global, donde predomina el montaje audiovisual en el desierto. En esta ciudad se explora en los estilos híbridos, orientados por la yuxtaposición de arquitecturas líquidas y reales que evidencian contextos socioculturales y ecológicos contradictorios, atados a lógicas y estéticas tradicionalistas y vanguardistas.

La ciudad hipermoderna es la fuente de la nueva iconografía urbana en la disyuntiva entre lo ideal y la evidencia escópica de lo concreto. En ambos puntos de vista, la imagen visual y virtual retroalimenta las condiciones materiales, tecnológicas y procedimentales de la realidad social observada. Por lo que sigue, en el binomio virtualidad/realidad, el "cuerpo habitante" y el "zombi" operan como metáforas del espacio de tensión social y urbana.

\section{Ruina fantológica}

Existen varias lecturas de la ruina fantológica, de las cuales se presentan distintos tipos de vestigios que resultan ser antagónicos. Interesa la existencia de una variedad de ruinas que se degradan o se olvidan.

La ruina fantológica corresponde a la arquitectura de vidrio y transparencia que disipa el aura de creación a causa de los procesos de industrialización. Una infraestructura moderna envejecida, desgastada y construida mediante roles, ideologías y modelos de conducta urbana, los cuales perduran de manera fugaz, pero no existen eternamente. Porque la existencia transitoria se marca en lo que aparece por un instante, que se esfuma, para volver a manifestarse sin horario previo en cualquier momento. Se trata de un espacio habitable y pasajero de muchas dimensiones y umbrales que emergió a principios del siglo XXI porque resulta funcional socialmente debido a la carencia y a la precariedad socioeconómica urbana.

Derivada de la idea de la ruina moderna, la ruina fantológica está conformada por edificios o estructuras que perdieron su función original, de manera que existen grietas carentes de procesos de restauración en vista de la desintegración física y química ocurrida a través del suceder del tiempo. Son lugares que aparecen con nuevas resemantizaciones coligadas a temáticas literarias, románticas o fantásticas. 


\section{Flaneurismo virtual ofigital}

¿Qué es el flaneurismo figital? Se define por la presencia de un "hipercuerpo" (Lévy, 2003:27) parecido a un dandismo virtual, que reconstruye ready made urbanos, percibidos en la pantalla y en la transacción inconsciente de un entorno de navegación interactivo, en cuyas operaciones se encuentra la especificidad de la imagen-objeto definida por la gestalt electrónica y el índice de la imagen técnica.

Recordemos que el flâneur es una invención burguesa sobre el caminante en París, capital del siglo XIX (Benjamin, 2005). Este personaje construye una geopoética narrada por la escritura de viaje (Lévy y Bouvet, 2018; Carpentier y Chartier, 2006) gracias a deambulaciones en la vida rutinaria de la urbeespectáculo, la cual fue edificada con perspectivas infinitas tomando en cuenta la proporción, la armonía y la simetría (Déotte, 2015) haussmannianas basadas en la ilusión, el lujo y el style. Así, se reconoce el ojo de un lector-consumidor en el contexto de la plusvalía, exhibida en grandes superficies: almacenes, exposiciones universales, vernissages, pasarelas y publicidad exterior.

El desplazamiento es la actividad del paseante (Baudelaire, 2010) por una ciudad repleta de novedades, fantasmagorías y estímulos pomposos, que recupera la capacidad de asombro en la locura del ver une folie de voir (Buci-Glucksmann, 1986), comenzando con el placer barroco.

En nuestros días, el flâneur global de la sociedad de la información es un cronista de periferias y de la ciudad-mundo, donde "los itinerarios urbanos son un modo de entretenimiento asociado a la mercantilización moderna y a su espectacularización en el consumo" (García Canclini, 1995:97) de vitrinas como espacios de exhibición.

\section{Turismo negro por Instagram}

Instagram es una forma de hacer sociedad mediante el álbum de un turismo negro. Registrando experiencias vedadas, motivaciones y actitudes exploradas por el urbex, se presentan escenarios censurados del desastre y del fin del mundo (Scott, 2015) en la ciudad. Marc Augé afirma que: "La ciudad presta una escenografía ejemplar: la evidencia simultánea de la inconcebible soledad y de la imposible sociedad, la evidencia de una amenaza que nunca se concreta por completo, la amenaza de la soledad, y de un ideal que no se cumple nunca realmente: la sociedad" (Augé, 1998:110).

En ese sentido, el valor social del cibernauta que hace turismo negro en la cuidad destruida se transforma en un personaje emotivo dentro de la escenografía del desastre, compuesta de rutas alteradas por los efectos del huracán Katrina (Rey y Rodríguez, 2009), permitiendo la segregación visual del downtown de Nueva Orleans a través de la apología del fetiche desde lo fotografiado (Scott, 2015). Un fetichismo comercial de la imagen ecológica, confrontada con la textualidad de Gutenberg (McLuhan, 1998), es resaltado por el relato publicitario de las agencias de viajes y por las noticias de las cadenas de televisión. Es decir, se transforma la tragedia de la inundación en archivo, en documentación histórica y en mercancía mediática, y se adapta la imagen audiovisual de la bladerunnerisation (La Rocca, 2013:64) de la cultura urbana. En efecto, el "ojo móvil y cinemático" (La Rocca, 2011:72) del urbex se extiende al espacio virtual de la violencia social por medio de la ficción.

En fin, el urbex como turista constituye el personaje de la ficción que emplea medios para tocar y reproducir imágenes de desesperanza mediante "la webtitud telecomunicativa" (La Rocca, 2013:270) difundida por la écran-global (Soulages, 2012:49). El caminar por el teléfono móvil (Márquez, 2015), deslizando los dedos, activa operaciones ópticas de la fascinación revivida y recreada. Específicamente, la imagenpantalla antropofágica de la experiencia turística no es solamente una superficie transparente, sino la condición opaca del contorno del dispositivo que se ejemplifica en la serie Black Mirror (2011), cuando el ojo curioso y voyerista del urbex opera en la narración geolocalizada. 


\section{Metodología zombi}

La Bitácora Zombi existe en el mundo real a través de un pequeño cuaderno de viaje en el ciberespacio. Empleando ambos medios, físico y virtual, constituye un tipo de escrito tecnológico y dispositivo web que recopila procesos epistemológicos, discursivos y proyectuales de la obra artística. La investigacióncreación registra, captura y examina resultados del juego técnico y visual del flaneurismo virtual y real, guiado por rutas de la cartografía de San José.

La sociología visual colabora, también, en el análisis de la imagen y en la observación oculocentrista, aportada por la técnica de la photo-elicitation acerca de zonas frecuentadas por estratos sociales en movimiento. Se representan las herramientas documentales y poéticas en directo, adaptadas a los comentarios hechos por el protagonista sobre los entornos de la urbe a partir de la imagen plástica y fotográfica.

La metodología zombi contribuye a problematizar el poder visual de la imagen mediante el conocimiento de una época contemporánea y de zonas de la ciudad en tanto que lugares de riesgo, delimitados por líneas fronterizas de carácter iconográfico y arquitectónico en la segmentación del espacio urbano de los sectores más problemáticos de San José Centro.

En general, en el devenir de la metodología se clasifican tres amplias etapas de exploración urbana que hacen de la obra de dibujo una comunicación intersubjetiva: deriva urbana, dibujo cromático in situ y plataforma de Instagram.

\section{Deriva urbana}

En esta primera fase se emplea la "deriva situacionista" (Debord, 1958), definida como ruta simulada y real que describe los desplazamientos ópticos en vivo, mientras se orienta la mirada por el espacio penetrado ya sea por la participación directa del ojo, sin intervención de la totalidad del cuerpo, o por medio del movimiento cinético, en lo anatómico, incluyendo las extremidades de los pies. La deriva corporal genera efectos provocados por el sudor y el esfuerzo físico recreando situaciones de ocio, supervivencia y turismo, a través de la subjetividad interna del sujeto caminante en un campo de desplazamientos a cielo abierto.

Por el lado digital y por medio de la conectividad dentro del paisaje electrónico, se reorganiza el macroespacio de San José, el cual continúa siendo un lugar de acceso a la dinámica de paseantes virtuales. De esta manera, la deriva urbana virtual corresponde a la navegación por Google Street View, localizado en Google Maps, al activar desplazamientos oculares en el paisaje electrónico. Concretamente, se aterriza hacia el macroespacio desde una visión de avión. Luego se accede al microespacio hecho por rutas peatonales segmentadas desde el punto de vista del pegman o avatar, lo que constituye la última estación del viaje.

Por eso, el encuadre visual de la progresión de fotografías capturadas y secuenciadas por cámaras multivisión, ubicadas en la parte superior de los autos de Google Street View, permite localizar la materialidad urbana en iconos reconocibles. Estos archivos móviles recopilan elementos del paisaje próximo a la calzada, accediendo a una rescritura de la narración temporal mediante recorridos en cadenas de fotos, aumentadas a nivel satelital, mundial y geográfico.

Entonces, se especifican tres estadios de descenso del flaneruismo virtual, yuxtaponiendo gradaciones de fotos que delimitan la visión aérea, a través de pequeñas aproximaciones hasta llegar al suelo de la calle. Estos estadios se identifican en relación con el acercamiento inicial, medio y último (Rojas, 2017), en el cual se llega al final a un punto de fuga de la vía que parte de la escala humana. Luego, se comienza una selección creativa de tomas visuales a nivel de la calle, donde se camina por los ojos de modo virtual gracias a la tecnología de conectividad en lugares observados.

Por eso, en las imágenes del "flaneurismo final" aparecen líneas de fuga de recorridos que indican marcas de rutas, mientras el ojo camina hacia la inmensidad. Seguidamente, se sistematizan los efectos fotográficos por zonas de cruces verticales y horizontales encontrados en el entorno, que indican planos zoom, planos americanos y panorámicos del paisaje seleccionado. 


\section{Dibujo cromático in situ}

En esta segunda etapa se prepara el proceso de creación, abstracción y composición del dibujo in situ delante de la pantalla y al frente del objeto por medio del sketch y el boceto gráfico. Al "bocetar" se valora la realidad percibida y explorada por el ojo-cuerpo, lo que da cuenta del uso expresivo de la herramienta.

La bitácora de dibujos conforma un atlas de imágenes semiabstractas de referentes sígnicos, usando patrones visuales de la ciudad-ficción que muestran la contradicción y la problemática social mediante la síntesis geométrica y cromática. El bocetear es una acción valorativa de la realidad percibida por el ojo-cuerpo.

En este acto se logra la personalización de contenidos desde la expresividad de la imagen, al permitir organizar elementos de zonas planas coloreadas (ver Imagen l) con intensidades diversas en la insinuación del movimiento urbano y la problemática de la investigación artística a través de la arquitectura y el entorno rastreado.

También, se introduce en esta etapa de croquis la segmentación de la imagen en fragmentos formales, introduciendo estructuras caóticas en la apariencia estilística. En fin, existe una lectura cognitiva y referencial del fenómeno urbano y artístico que implica la toma de decisiones técnicas en el campo del arte plástico.

\section{Plataforma de Instagram}

En la tercera etapa se suben los dibujos a Instagram, ${ }^{2}$ dispositivo panóptico de tipo Kodak Instamatic, el cual activa el proveedor de información geográfica en la distribución y gestión de recorrido virtual. Asimismo, esta plataforma digital de archivos informáticos se convierte en el medio de difusión por el hashtag, que etiqueta y almacena metadatos en el repositorio de recuperación de imágenes digitales (ver Imagen 2) en el entorno mediático.

Estas tres etapas descritas con anterioridad replantean la "ruina moderna" en San José, demarcando zonas de conflicto, claramente identificadas y localizadas; momentos que construyen la imagen del espacio urbano desde el lugar de prácticas creativas. Así, se establece una narrativa y una ficción de la realidad con la posibilidad de ver la arquitectura de la ciudad de San José compuesta de ruinas modernas. Esas ruinas validan el estatus de una demarcación por zonas de conflictos culturales y de degradación social. A partir de una identificación de sectores divididos por jerarquías sociales, se piensa en el uso plástico del espacio, así como en el empleo de modelos estilísticos conformadores de entornos construidos por la mirada y la visión.

Estos aspectos mencionados sobre la ruina moderna se identifican con los lenguajes audiovisuales e intermediales de la imagen digital que contienen estructuras psicoespaciales, las cuales se identifican con la cultura material desde el patrón, la escala, los frames, el montaje, la repetición, la simulación y la edición (Darley, 2002) de la imagen urbana.

En consecuencia, la metodología zombi ${ }^{3}$ es medular para integrar la ruina moderna emparentada a la estética del espacio público desde los estudios urbanos.

\section{Deriva urbana y rutas de la cartografía de San José}

Para introducir las rutas cartográficas es necesario contextualizar, de manera histórica y espacial, la importancia de la ciudad de San José, capital de Costa Rica, lo cual revela la Bitácora Zombi.

Fundada en 1738 en el Valle Central, se consolida como eje donde se concentra el comercio a partir del "capitalismo agrario del siglo XIX, basado en el café y el banano" (Molina y Palmer, 1997:1). En ese momento se fortaleció la construcción de fachadas e interiores de una arquitectura domiciliaria, que inspira imágenes diegéticas sobre fantasías, apariciones y fantasmas. Un fantasma del capitalismo mercantilista (Vidal, 2013:52) que nos ve y nos observa mientras se habita y se camina.

Actualmente, San José es la ciudad más populosa, extensa y céntrica del país. Tiene la mayor concentración de servicios, así como de industria, localizada en la periferia del casco histórico y en los alrededores. Presenta una variable calidad del espacio urbano por 
metro cuadrado de construcción. Compuesta de zonas de alta densidad poblacional, se despliegan sectores socioeconómicos heterogéneos y áreas de contrastes socioculturales en relación con el resto del territorio, lo que limita los confines de paisajes y geografías agrícolas y en estado natural.

Con la introducción de tendencias arquitectónicas industriales, a principios y mediados del siglo XX la capital comenzó a tener una cara con líneas verticales y horizontales al introducir la forma urbana y arquitectónica limpia de los estilos modernistas, con gran influencia de las tendencias de la ingeniería del acero, el hierro y el vidrio expuesto. El triunfo del urbanismo latinoamericano de vocación racionalista permite la incorporación del cubo en contraposición al ornamento de origen neoclásico y neogótico, determinante en la construcción de la vivienda popular de madera y de edificios públicos suntuarios como el Teatro Nacional, construido en 1897.

Aún hoy, el centro de la capital está organizado a partir de una cuadrícula renacentista de herencia colonial compuesta por el parque central, la iglesia y la zona gubernamental. Áreas unidas por bulevares a la francesa como el Paseo Colón, la Avenida Segunda y la Avenida Central, que activan nodos en el centro histórico, donde grandes poblaciones se desplazan por razones laborales, de consumo y de tránsito vial que se congestiona en horas de embotellamiento. Por tanto, el centro es un lugar ideal para realizar una investigación visual a partir de caminatas delimitadas, al ofrecer estímulos estéticos, culturales y económicos.

Dicho de otro modo, es de suponer que los resultados artísticos de la ruta devienen de la interpretación visual del paisaje. En este último punto nos preguntamos: ¿cómo opera la Bitácora Zombi en tanto que lectura visual a partir de las derivas de San José?

\section{Derivas del patrimonio republicano en ruinas fantológicas: Parque Central, Asamblea Legislativa y Plaza de la} Democracia

El alcance de esta deriva asume el caminar dentro del patrimonio republicano, el monumento y la ruina fantológica, dialogando con el pasado y el futuro. El espacio político encarna los símbolos patrios, el monumento y la memoria de héroes desde una cartografía cultural (Molina y Palmer, 1992).

La articulación de la micropolítica delespacio público con la imagen republicana conlleva la incorporación de aspectos literarios, académicos, educativos, físicos y comunicacionales de la historia biográfica de la cultura urbana, pensando el habitar como representación de un espacio moderno cubicular y neobrutalista.

En ese sentido, se accede al poder de la representación de la ciudad y de los espacios públicos construidos por la licencia estatal y por el discurso oficial electoral, basado en grandes relatos inventados por la modernidad republicana y funcionalista.

\section{Derivas del modernismo-zombi-formalista: Avenida Central}

La presencia de formas muertas del arte en lo urbano denota la disparidad de la infraestructura, juzgando lo patrimonial en el curso de la cultura costarricense del siglo XXI.

La estética zombi se yuxtapone a la escultura moderna en el espacio social, que incita al constante retorno de espectros formales y ficcionales en la mutación de San José. Primordialmente, la estética zombi conlleva una doble vía en términos de una representación visual y apela, a su vez, al sentido original de la aestheticus, la cual orienta una sensibilidad y percepción acerca de la anomalía del paisaje urbano.

Todo lo anterior es una metáfora que se traslada al conflicto simbólico, donde la estética zombi conforma, pues, un lenguaje de la pulsión urbana, identificada por mecanismos de la impureza, la suciedad y el hedor, al cuestionar principios de armonía y proporción propios de la belleza visual, pero definitorios de la dimensión de la muerte.

El arte público de la Avenida Central, principal vía de la capital, conforma una ecología zombi compuesta por la transición entre la naturaleza de cuerpos contagiados sin contención médica, conformando cepas de microorganismos que viven en sistemas de intercambio e interacción simbólica e histórica. Una catástrofe infecciosa de la Avenida 
Central se definiría por la combinación entre la naturaleza contagiosa de la figura del zombi, el pasado en el presente - anacronismo- de los espacios, la economía informal, la representación artística e iconografía publicitaria - anuncios electrónicos, vallas digitales, arte bidimensional y escultura urbana-y los cuerpos caminantes - trabajadores, travestis, pastores neopentecostales, músicos callejeros, mimos, pinta caritas, vendedores ambulantes, animadores de tiendas, turistas norteamericanos, etcétera- en un bulevar habitado por los microorganismos de la basura.

Se muestra, además, el caos del imaginario de San José mediante el selfie experience de la fotografía con el arte público: testimonio inmortal de la vida privada del peatón registrándose en el "reflectograma" por la "noosfera" (Fontcuberta, 2016:97) en la temporalidad, la ubicuidad y la porosidad de la imagen espectral de lo reciente perpetuo.

\section{Derivas del cuerpo bio-geopolítico del migrante: Parque de la Merced}

En la deriva del cuerpo biopolítico del migrante, el dibujo representa una estética geopolítica en el jardín, mostrando puntos de vista del rostro arquitectónico y esqueletos ingenieriles, donde están presentes los cuerpos flotantes de la migración nicaragüense y centroamericana en tanto que tribu supranacional, que aborda temáticas como la ilegalidad, la pobreza, la economía informal, el conflicto binacional, la vigilancia estatal y la xenofobia sufrida por el inmigrante clandestino en la privación del principio de universalidad.

El otro-extranjero que frecuenta esta zona no tiene el estatus del flâneur privilegiado, al contrario, es un habitante de la subsistencia, un proletario del territorio que reclama un nivel de ingreso y bienestar mínimos y hace rescatar el humanismo, la solidaridad y la sensibilidad. Es aquel personaje que vive en estado de urgencia adeudando los papeles en regla. Viola los muros y fronteras arquitectónicas, terrestres, marítimas o aéreas sin permiso oficial de entrada o expirado. No tiene un estatus de legalidad en entornos extranjeros heterodoxos, en los cuales se desarrollan ambientes cargados de incertidumbre, hostilidad social, explotación laboral y discriminación ideológica y cultural.

En fin, este emigrante trata a toda costa de conservar la identidad cultural y física, ocultando la localización de sus desplazamientos y encuentros colectivos que realiza diariamente, protegiéndose de las autoridades migratorias en todo momento. Desde el punto de vista social, el inmigrante-peatón es desclasado, a pesar de su deseo, por el ocio burgués, y es subordinado por medios de reproducción social.

Por otro lado, el inmigrante digital podría ser un inmigrante ilegal, no obstante, se encuentra en un territorio virtual donde reina un universo imaginario. Puede ser perfectamente un ilegal en un universo físico al poseer una corporeidad identificable, que detenta un estatus de internauta, en el contexto iconográfico electrónico, navegando en el interior de la pantalla sin ser perseguido por su condición ilegal.

Por otro lado, el inmigrante existe porque coexiste el lugar de encuentros con la arquitectura y la mueblería urbana. Por el hecho de mencionar la posición geográfica se determina que es el lugar de convivencia cultural.

El dibujo de la Bitácora Zombi no refleja necesariamente los cuerpos migrantes en el espacio, sino las fachadas arquitectónicas que son representadas con las técnicas del pilot, cruces de líneas de fuga, superposición de trazos de detalles constructivos y colores estridentes. Todos esos elementos urbanos y plásticos son la metáfora del inmigrante, que vive y circula en el Parque la Merced.

\section{Derivas de la zona de cuerpos-sin hogar de los itinerantes:} Rincón Cubillos, Pitahaya, Coca Colay Paso de la Vaca

Cuando se realiza el recorrido por esta zona de destierro se observa y se muestra la marginalidad urbana del desposeído. Marginalidad producto de las fallas del capitalismo urbano, la cual se distribuye en zonas de conflictividad social a partir de una microdinámica del habitar. Esas zonas de conflictividad del hábitat se deben a la falta de empleo y oportunidades. 
Enfermedades mentales, físicas y epidemiológicas, junto con el tráfico de drogas, influyen en los espacios inertes, derretidos, desarticulados y abandonados, generando problemas de salud pública.

El turismo negro por estas zonas se asume desde el flâneur-observador que, a partir de una posición de privilegio, explora el riesgo del territorio, capturando la imagen de destino de la pauperización y de la marginalidad del hecho social. Por tanto, se evidencian en esa ruta figuras metafóricas del espacio de la inseguridad y de un futuro incierto, articulando las lógicas de la exclusión, el abandono y la indiferencia.

Efectivamente, se plantea una hauntología de lo urbano y del espacio arquitectónico. Lo hauntológico se define en lo fantasmagórico, producido por Internet, y en la cultura popular y urbana de San José, cultura colmada de espectros visuales donde el desplazamiento corporal y óptico activa mecanismos de aparición de detalles de las texturas urbanas en la desaparición y el alumbramiento, destacando sobre los envejecidos y deslucidos frontispicios geométricos de estilo Art déco, racionalista y brutalista de barrios.

\section{Derivas en Barrio Escalante}

Las derivas en Barrio Escalante muestran un interés en el desarrollo de la vivienda vertical tipo loft y los servicios simbólicos de estatus, orientados al urbanismo neoliberal como fantasmagoría (Benjamin, 2005).

Se acentúa el aburguesamiento (Rosler, 2017) del espacio público, concebido a partir del discurso político-municipal de revitalización urbana, iniciado por recorridos en la cartografía heterogénea, la cual es administrada por planificadores, constructores, ingenieros, arquitectos, diseñadores, artistas y políticos.

Barrio Escalante virtual se renueva por plataformas electrónicas y modelos sociales en la cultura mediática. Allí, el régimen visual de la imagen urbana reproduce micronarraciones provocadas por recursos orientados por una renta digital, la cual Srnicek define como: "el sector más dinámico de la economía contemporánea, un área de la que supuestamente emerge innovación constante y que parece estar dirigiendo el pensamiento económico hacia delante" (Srnicek, 2018:13).

Por último, la actividad del turista de Barrio Escalante, contraria al turismo negro, conduce el data de la sociabilidad urbana mediante una crónica de la movilidad del égoportrait en la atracción de entornos bellos y felices. Esa crónica de la experiencia apolínea verifica el nivel de consumo, el estilo vida, el estrato y la clase social vinculados al uso de plataformas de los gigantes de la Web -Google, Apple, Facebook, Amazon, Microsoft-

\section{Conclusiones}

A lo largo del artículo se reflexiona sobre el desarrollo teórico y la metodología zombi con un enfoque centrado, primeramente, en el régimen escópico, la teoría de la imagen y la visualidad urbana. Situando la paráfrasis de la ciudad como evidencia visual necesaria, se llega a la experiencia social citadina desde la narración fingida.

Se comprende, entonces, la ciudad posmoderna provista de ruinas modernas asociadas a lo monstruoso y lo orgánico, donde ocurren desplazamientos dentro de la ecología zombi del miedo al modificar la lectura del espacio urbano capitalista. Estas apariciones históricas y literarias reafirman la recuperación de la mirada y la representación artística. Se vislumbra, pues, la ruina fantológica señalando, en la dimensión geográfica, la desilusión del progreso en un pacto ficcional, el cual transforma la imagen virtual y real de un San José en conflicto con la imagen social.

Otro aspecto abarca el caminar, el flaneurismo y la deriva, que narran el cuerpo urbano y político en la intersubjetividad y generan travesías socioemotivas mediante imágenes surgidas del diario mental o el cuaderno de creación. Los territorios urbanos de San José se asemejan a un paisaje penetrable en lo fugaz, acentuando el microrelato del turista, visitante, habitante o inmigrante en el contexto del poscapitalismo visual y de la sociedad de la vigilancia.

Asimismo, se entrecruza la tecnología de Internet, la 
virtualidad, la geolocalización y las plataformas de redes sociales como Instagram. Se rescata el desplazamiento virtual debido al flujo visual urbano que desde lo vacío, lo poroso, lo simulado, lo mediático y el ensueño es base de la Bitácora Zombi. En este sentido, se evidencia la desesperanza y la resistencia política. Allí, se delega la intimidad del sujeto urbano mediante el dispositivo tecnológico y la exploración libre con la imagen-pantalla en tanto que performance de una geopoética urbana.

La metodología zombi como tal contiene un discurso señalado en la expresión plástica y pictórica, por lo tanto, es conveniente el empleo de una estrategia de comunicación académica acompañada por la ejecución técnica mediante el óleo, el marcador, la acuarela y el acrílico. La imagen dibujada, el texto visual y el discurso componen los procedimientos mixtos del urban sketch. En su configuración simbólica, sígnica y material se simula el lenguaje del spray y del grafiti, hacia su imagen digital.

Específicamente, hay una retroalimentación de la semiótica visual en la interpretación de la imagen y de la práctica artística en el espacio. Así, emparentando el estudio de lo icónico con el mundo físico y virtual se establece una sintaxis discursiva en la exploración geolocalizada. Además, se permite conocer la problemática urbana, compuesta de propiedades escalares, elementos de proporción, características expresivas de materiales, sustratos e instrumentos y dispositivos visuales.

Por consiguiente, la metodología zombi abarca la misión de ideas a través de la investigación-acción mientras se camina a pie y orbitalmente, al profundizar en la exploración y la observación de datos visuales emanados del flaneurismo.

Para finalizar, la metodología zombi participa en la acción teórica del desplazamiento y de la ejecución técnica, dispuesta por la deriva urbana y su imagen gráfica en tanto que herramienta expresiva y conceptual. El dominio del mundo real y del espacio on line por la mediación se efectúa en la diversidad de atmósferas metafóricas y narrativas capturadas por la bitácora de viaje y de vida.

\section{Notas}

${ }^{1}$ Ver: https:/www.instagram.com/explore/tags/bitacorazombi/ 2 Ver: https://www.instagram.com/rodolforojasrocha/

3 La metodología zombi se inserta, además, en uno de los ejes teóricos de investigación, desarrollado en el proyecto Pry01-670-2018 inscrito en IIArte de la Facultad de Artes de la Universidad de Costa Rica, denominado Aula Negra: laboratorio de la imagen plástica, la pantalla y el performance; cuyo eje temático investiga sobre los modelos de producción mediática y las implicaciones sociales, estéticas y artísticas de los dispositivos de pantalla y proyectores de imágenes, en grandes y pequeños formatos, en la comunidad, vinculando la imagen audiovisual, la imagen geolocalizada, el espacio plástico, el cuerpo, el andar y la iconografía urbana, natural en la doble dimensión phygital.

\section{Referencias}

Amendola, Giandomenico (2000). La ciudad postmoderna: magia y miedo de la metrópolis contemporánea. Madrid: Celeste Ediciones.

Augé, Marc (1998). El viaje imposible: el turismo y sus imágenes. Barcelona: Gedisa.

Baudelaire, Charles (2010). Le peintre de la vie moderne. París: Fayard/Mille et Une Nuits.

Baudelaire, Charles (2017). Le spleen de Paris. París: Flammarion.

Benjamin, Walter (2005). Libro de los pasajes. Madrid: Akal. Benjamin, Walter (2013). L'ouvre d'art à l'époque de sa reproductibilité technique. París: Éditions Allia.

Brea, José Luis (2006). "Estética, historia del arte, estudios visuales". En Estudios Visuales, 3, 8-25.

Buci-Glucksmann, Christine (1986). La folie du voir de l'esthétique baroque. París: Galilée.

Buci-Glucksmann, Christine (2003). Esthétique de l'éphémère. París: Galilée.

Careri, Francesco (2002). Walkscapes: el andar como práctica estética. Barcelona: Gustavo Gili.

Carracedo,JoséDavid(2002). "Lavigilanciaenlas sociedades de la información. ¿Un panóptico electrónico?”. En Política y Sociedad, 39(2), 437-455. 
Carpentier, André y Daniel Chartier (2006). Nomades, voyageurs, explorateurs, déambulateurs: les modalités du parcours dans la littérature. París: Editions L'Harmattan.

Darley, Andre (2002). Cultura visual digital. Espectáculo y nuevos génerosen los medios de comunicación. Barcelona: Paidós.

Davis, Mike (2001). Más allá de Blade Runner: control urbano: la ecología del miedo. Barcelona: Virus.

Davis, Mike (2007). Ciudades muertas: ecología, catástrofe y revuelta. Madrid: Traficantes de Sueños.

Debord, Guy (1958). Teoría de la deriva. Internacional situacionista, 1. Madrid: Literatura Gris.

De Miguel, Jesús M. (2003). "El ojo sociológico”. En Reis, 101(3), 49-88.

Déotte, Jean-Louis (2015). "Walter Benjamin: la perspective comme fantasmagorie". En Appareil, 15.

Fernández Gonzalo, Jorge (2011). Filosofía zombi. Barcelona: Anagrama.

Fontcuberta, Joan (2016). La furia de las imágenes: notas sobre la postfotografía. Barcelona: Galaxia Gutenberg.

Foucault, Michael (2007). Los anormales. Buenos Aires: Fondo de Cultura Económica.

Fukuyama, Francis (1989). "The end of history?". En The National Interest, 16, 3-18.

García Canclini, Néstor (1995). Consumidores y ciudadanos: conflictos multiculturales de la globalización. México: Grijalbo.

Jay, Martin (2003). Campos de fuerza: entre la historia intelectual y la crítica cultural. Buenos Aires: Paidós.

Lacan, Jaques (1966). Écrits I. París: Éd. du Seuil.

La Rocca, Fabio (2011). "Techno-øil: jeux de formes et d'images". En Sociétés, 111, 71-79.

La Rocca, Fabio (2013). La ville dans tous sesétats. París: Cnrs.

Lévy, Bertrand y Rachel Bouvet (2018). "Littérature et géographie: dialogue autour du récit de voyage”. En Le Globe, 158, 5-23.

Lévy, Pierre (2003). ¿Quées lo virtual?. Barcelona: Paidós.

Limare, Sophie (2015). Surveiller et sourire: les artistes visuels et le regard numérique. Montreal: Les Presses de l'Université de Montréal.

Márquez, Israel (2015). Una genealogía de la pantalla: del cine al teléfono móvil. Barcelona: Anagrama.

McLuhan, Marshall (1998). La galaxia gutenberg. Madrid: Círculo de Lectores.
Mestre, Abel y Sylvia Zappi (2020). "Dans la fiction postapocalyptique, le «monde d'après » n'est presque jamais solidaire, pacifique et collectif. Le Monde". En Le Monde, 21 de abril. Disponible en: https://tinyurl.com/ ya7e $8 a 4 b$

Mitchell, W.J.T. (2014). Queveulent les images? Une critique de la culturevisuelle. Dijon: Les Presses du Réel.

Molina Jiménez, Iván y Steven Palmer (1992). Héroes al gusto y libros de moda. Sociedad y cambio cultural en Costa Rica (17501900). San José: Porvenir.

Molina Jiménez, Iván y Steven Palmer (1997). Historia de Costa Rica: breve, actualizada y con ilustraciones. San José: Universidad de Costa Rica.

Platzeck, José Gaston (2016). "El monstruo y el poder: un diálogo entre biopolítica y zombies”. En Representaciones. Revista de Estudios sobre Representaciones en Arte, Ciencia y Filosofía, 12(1), 77-94.

Platzeck, José Gaston y María Andrea Torrano (2016). "Zombis y cyborgs: la potencia del cuerpo (des) compuesto". En Outra Travessia, 8, 235-253.

Rey Castro, Alberto y Gonzalo Rodríguez (2009). "Turismo de desastres: aproximación a la explotación turística del desastre del Prestige en la Costa da Morte". En Revista Galega de Economía, 18(2), 1-20.

Rojas Rocha, Rodolfo (2017). "El flaneo virtual a través de Google Street View como una práctica artística”. En ESCENA. Revista de las Artes, 76(2), 109-124.

Rosler, Martha (2017). Clase cultural: arte y gentrificación. Buenos Aires: Caja Negra.

Scott, Diane (2015). "Retour des ruines". En Vacarme, 70, 23-46.

Solnit, Rebecca (2015). Wanderlust: una historia del caminar. Madrid: Capitán Swing.

Soulages, Jean-Claude (2012). "L'image écran, de la toile à l'interface". En MEI. Médiation et Information, 34, 43-52.

Srnicek, Nick (2018). Capitalismo de plataformas. Buenos Aires: Caja Negra.

Tomás Ferré, Facundo (1998). Escrito, pintado: dialéctica entre escritura e imágenes en la conformación del pensamiento europeo. Madrid: Visor.

Vidal, Bertrand(2013). "Leszombies de Detroit:linquiétante étrangeté des ruines modernes”. En Societes, 1(119), 49-56. 
Imagen 1. Bitácora Zombi

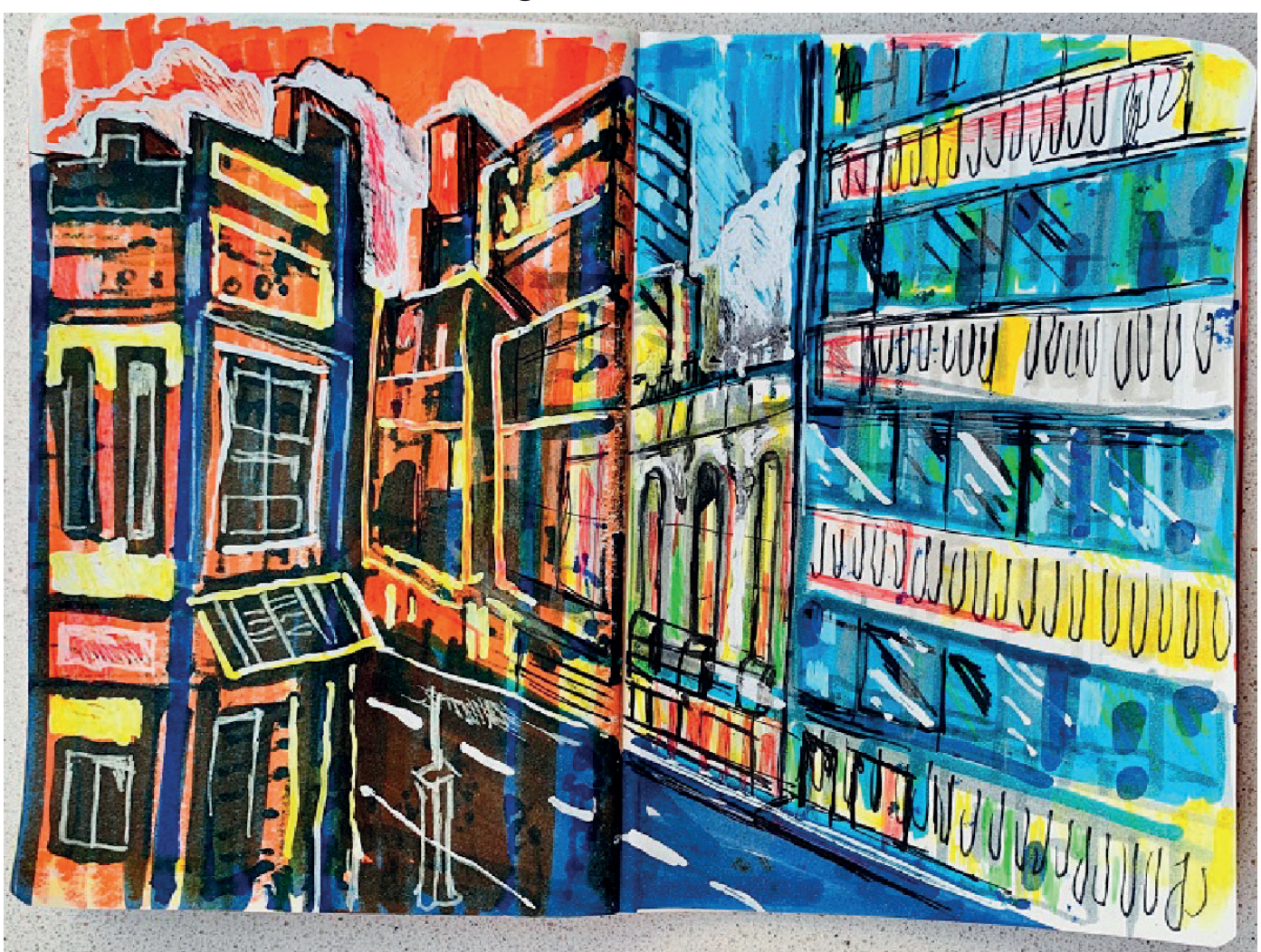

Fuente: Rodolfo Rojas Rocha. Pilot sobre sketchbook, 2020. https://www.instagram.com/explore/tags/bitacorazombi/

\section{Imagen 2 Bitácora Zombi en la plataforma Instagram}

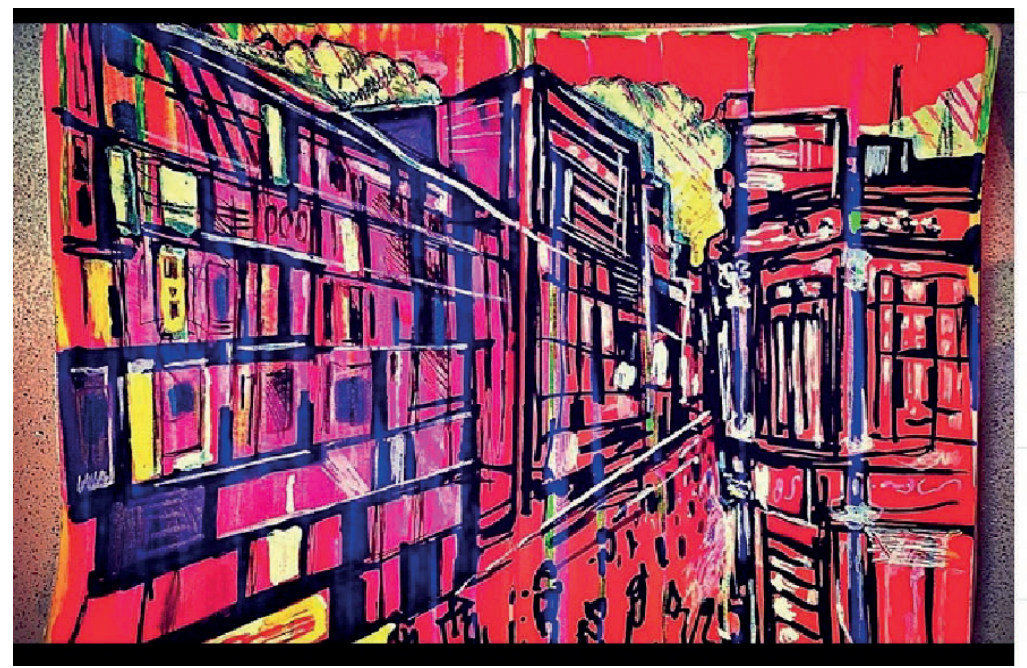

rodolforojasrocha

Boulevard Avenida Central- Esquina Calle ....

rodolforojasrocha De la serie
Bitácora Zombi, "perspectivas
simbólicas compuestas de
significantes y materialidades que
evidencian la presencia de una
arquitectura fantasma y moderna en
desuso, cuya función aún persiste,
un espacio donde el andar se torna
masivo, irregular y desenfadado"
\#bitacorazombi \#rodolforojasrocha
\#avenidacentralcostarica
\#ruinamoderna \#urbex
W

Q Liked by michael.rs02 and $\mathbf{3 7}$ others MARCH 1

Fuente: https://www.instagram.com/p/B9MUEtMn-ry/ 